\title{
DETERMINING CONSUMERS' INTENTION TO USE UNIT TRUSTS
}

\author{
Chantal Rootman* \\ Nelson Mandela Metropolitan University
}

Received: September 2015

\author{
Janine Krüger* \\ Nelson Mandela Metropolitan University
}

Accepted: February 2016

\begin{abstract}
The savings rate among South Africans is too low, and increasing the savings rate is critical for the financial wellbeing of citizens and for the country. Many South Africans do not make use of formal savings products, including unit trusts. However, there is a need to increase the use of unit trusts and thus the savings rate, and ultimately the financial wellbeing of consumers. Unit trusts are welldesigned savings/investment vehicles, allowing for small investment amounts with affordable cost structures catering for consumers with different risk profiles. Therefore this study will focus on investigating consumers' perceptions of unit trusts by identifying the factors which influence consumers' intention to use unit trusts as an investment vehicle. A quantitative study was employed and for the empirical investigation a convenience sample of 509 respondents completed a selfadministered, structured questionnaire. The data was quantitatively analysed and the main results showed that the Accessibility and Benefits of unit trusts are the most important factors influencing consumers' Intention to use unit trusts. The strategies explained in this study may assist financial service providers in encouraging consumers to use unit trusts as an investment vehicle. This may increase the country's savings rate and ultimately improve the financial wellbeing of South Africans.
\end{abstract}

Keywords

Unit trusts; accessibility; benefits; cost structures; savings, perceptions, behaviour

*Prof C Rootman is professor in the Department of Business Management, Nelson Mandela Metropolitan University, South Africa. [chantal.rootman@nmmu.ac.za]

\#Dr J Krüger is a senior lecturer in the Department of Business Management, Nelson Mandela Metropolitan University, South Africa. 


\section{INTRODUCTION}

According to Roberts, Struwig and Gordon (2014:1), the Financial Services Board (FSB) in South Africa is concerned about the financial wellbeing of the country's citizens, as the organisation aims to help South Africans to "manage their personal and family financial matters soundly". This means that proper financial planning and appropriate financial behaviour is needed. Good financial planning relates to setting financial goals, aiming to achieve these goals, preferring long-term saving options and having saved recently (Roberts et al., 2014:69). This shows that one's financial behaviour, and thus financial wellbeing, is linked to one's savings behaviour (Roberts et al., 2014:62).

South Africa's low savings rate, both in terms of individual household savings and the national savings rate, is a concern for the country's government (Incentivising non-retirement savings, 2012:3). Higher levels of individual household savings assist households, especially those in lowto-middle income groups, to be financially more secure and thus less vulnerable to income and expenditure volatility (Karlan, Ratan \& Zinman, 2014:36). In addition, a higher national savings rate reduces a country's dependence on foreign capital as well as ensures higher investment rates, higher economic growth and job creation (Incentivising non-retirement savings, 2012:3). However, South Africa's $15 \%$ national savings as a percentage of GDP is much lower than the averages of $34 \%$ in other developing countries, and $34 \%$ worldwide (Mongale, MukuddemPetersen, Petersen \& Meniago, 2013:519). The individual household savings rate in South Africa has decreased over a long period due to the high unemployment rate, low income levels as well as the increased availability of credit (Aron \& Muellbauer, 2011:3). This also led to the increased indebtedness of the country's households (Incentivising non-retirement savings, 2012:6). For example, in 2011 , debt consumed nearly $75 \%$ of South Africans' disposable income, and these too high levels of indebtedness increase households' financial vulnerability (Incentivising nonretirement savings, 2012:7).

Despite the current low savings rate, among the reasons for saving, South Africans list precautionary reasons, saving towards education and housing expenses, saving for retirement and saving to pay off debt. However, recent research has shown that most individuals do not save enough for the future (Incentivising non-retirement savings, 2012:7-9). Roberts et al. (2014:35) concur by stating that many South Africans find it difficult to save, as the survey by Roberts et al. (2014:36) in 2013 revealed that $44 \%$ of the South African respondents had no savings plan.

In addition to South Africans limited ability to save, the low savings rate might also indicate the existence of entry barriers, similar to those in other countries (Karlan et al., 2014:37), for saving with financial service providers (Roberts et al., 2014:36). Mongale et al. (2013:528) suggest that barriers to saving should be eliminated. Employment and income insecurity as well as the high cost of living in South Africa might be barriers for investments in formal savings products (Roberts et al., 2014:44), including unit trusts. This is evident in the survey by Roberts et al. (2014:44-45), as only a minority (33\%) of respondents have heard of unit trusts and only $2 \%$ of respondents have invested in unit trusts in 2013 . Only a slight increase is evident, as $1 \%$ of respondents invested in unit trusts in South Africa in 2012 (FinMark Trust, 2012:15). A study by Saini, Bick and Abdulla (2011:307) showed that $59 \%$ of the respondents did not invest in unit trusts. It is also evident that participation in all types of formal savings products has declined over time (Roberts et al., 2014:45). Despite these statistics, Collins and Morduch (2007:5) argue that there is a need for savings products for low-income households. Karlan et al. (2014:37) concur that poor citizens 
often have a high demand for savings. Sithebe (2014:79) also identified a need to offer more savings products to the market.

\section{PROBLEM STATEMENT}

Given the importance of saving, the low current savings rate and the need for savings products such as unit trusts, it is important to encourage consumers to use unit trusts as an investment vehicle. Therefore, it is essential to investigate the perceptions of consumers on the aspects (including benefits, accessibility and cost structure) relating to unit trusts, and as such identify the factors which influence consumers' intention to use unit trusts as an investment vehicle. By identifying these factors, consumers could be rightly encouraged to use unit trusts. This may increase the country's savings rate and ultimately improve the financial wellbeing of South Africans.

Thus, the problem statement of this study is formulated as a question:

Based on consumers' perceptions, which aspects influence consumers' intention to use unit trusts?

\section{OBJECTIVES OF THE STUDY}

The primary objective of the study is to investigate consumers' perceptions of unit trusts by identifying the factors which influence consumers' intention to use unit trusts as an investment vehicle. By understanding consumers' perceptions of unit trusts, and by knowing which factors influence consumers to possibly consider unit trust investments, recommendations can be proposed to financial service providers, including independent financial advisors/planners. The implementation of these recommendations on how to encourage the use of unit trusts might increase South Africa's savings rate and improve citizens' financial wellbeing.

\section{LITERATURE REVIEW}

\subsection{Savings and investments}

In the most basic sense, saving occurs when a person spends less than what he/she earns in order to have more funds available in the future (FSB, n.d.:1). According to Soman and Cheema (2011:S20), there is a significant need to increase savings rates in the current economic climate, both in developed and in developing countries - which includes South Africa. The household savings rate in South Africa is relatively low when compared to international standards (Precious \& Asrat, 2014:183). In 2010, South Africa's household savings rate as a percentage of household disposable income was $-0.3 \%$ (OECD, 2011:63). According to Precious and Asrat (2014:184), the South African Reserve Bank calculated the country's household savings as a percentage of GDP to be at a negative average of $-0.20 \%$ for the period $2009-2011$. An official report indicates that South Africa's national savings rate as a percentage of GDP stood at $13.5 \%$ in 2013 (Jonas, 2014:2). Later statistics put South Africa's national savings rate as a percentage of GDP at $15 \%$ currently (Mongale et al., 2013:519). However, the household savings rate reached 0\% in South Africa during 2013 (Sithebe, 2014:3), and the latest statistics reveal that the household savings 
rate is a mere $1.7 \%$, as from mid-year 2013 (Jonas, 2014:2; SAICA, 2013). Therefore, it is important to create a savings culture among South Africans by taking into account various issues which may prevent citizens from saving.

South Africa has a poor savings culture due to its high unemployment rate and a large uneducated population (Dempsey, 2011:1). Unemployed citizens have no or low income levels, have often not received education on the need for saving and therefore the savings culture in South Africa is poor. The poor saving culture in South Africa leads to consumers being financially vulnerable (Incentivising non-retirement savings, 2012:3), because they do not save enough income for a later stage. The poor savings culture leads to South African consumers living in debt and using more credit than what they save (Maisel, n.d.: 2). According to Jonas (2014:4), debt to disposable income in South Africa has almost doubled from 1980 to 2013, from $41.9 \%$ to $75.2 \%$. Lusardi, Mitchell and Curto (2010:359) concur that consumers have high levels of debt. Therefore, interest rates and the fluctuation thereof will also influence citizens' savings culture. In addition, Braunstein and Welch (2002:44) highlight the increase of consumers' debt levels, and the decline in the already low consumers' saving rate.

In 2012, only $25 \%$ of South Africans saved on a regular basis (FinMark Trust, 2012:36). The latest statistics from FinScope South Africa shows that $68 \%$ South Africans do not save at all (FinMark Trust, 2014:7), meaning that still only $32 \%$ save regularly. In addition, it is evident that only $15 \%$ of South Africans have a formal savings product from a non-bank financial service provider, and this type of product might be an unit trust (FinMark Trust, 2014:7).

The $32 \%$ of South Africans that do save, mainly at formal financial service providers, indicate that the main drivers for saving stem from the fact that funds might be needed in the future for emergencies, funeral costs, food, education, family members and retirement (FinMark Trust, 2014:7; Jonas, 2014:1). Of the $8 \%$ of South Africans who saved before, but are no longer saving in 2014, most indicate that they could not afford saving anymore (FinMark Trust, 2014:7).

Maisel (n.d.:9) highlight that the low savings rate and the high use of debt in South Africa suggest that the financial behaviours of consumers need to change. According to Lusardi et al. (2010:358), increased savings will contribute to a better quality of life and a better future as more informed financial decisions will be made. Lewis and Messy (2012:7) concur that savings are important to one's financial wellbeing.

\subsection{Unit trusts as an investment vehicle}

Various savings/investment vehicles, each with its own advantages and disadvantages, are available to citizens and enable them to save for the future. Investment vehicles include shares, bonds, property, cash, unit trusts, exchange traded funds (ETFs) and exchange traded notes (ETNs) (Oldert, 2014:111; PSG Online, 2014a). For the purpose of this study the focus will be on unit trusts, being an investment vehicle which assists consumers with their financial savings goals. Often units trusts are referred to as 'mutual funds', however, this is usually regarded as the term used in the United States of America (USA) (Oldert, 2014:34). Unit trusts were first designed as an investment vehicle for 'ordinary' people, to give them access to the JSE as the average investor does not usually have sufficient funds to purchase a range of quality shares (Oldert, 2014:33,42). The FSB regards unit trusts as a viable savings option for individuals, available from various financial service providers (FSB, n.d.:1).

A unit trust is a type of collective scheme investment (CIS) where an investor own part of a diversified, professionally managed portfolio of securities as he/she invested a once-off or 
monthly amount of funds (Oldert, 2014:42). Unit trusts are also defined as investment vehicles which are professionally managed portfolios of shares, listed property investments, variable interest investments, and multi-class portfolios (Mibiola, 2013:15; PSG Online, 2014b). Specifically, a unit trust pools the money of many people and invests it in shares, bonds, money market securities and other types of securities (Oldert, 2014:50). The pool of investments is divided into identical units or sections of investment interests, and each unit contains the same share of the assets in the total portfolio (Oldert, 2014:50). Unit trusts are classified according to the classification levels of the Association for Savings and Investments (ASISA) (Faurie, 2014; Stokes, 2008). Furthermore, unit trusts are divided into eight different types of funds (PSG Online, 2014b; PSG Online, 2014c). The eight types of funds include Funds of funds, Multi-managed funds, Index funds, Feeder funds, Shari'ah compliant funds, White label funds, Hedge funds, and Exchange traded funds.

\subsection{Characteristics of unit trusts}

When considering investments in unit trusts, it is important to be knowledgeable about the benefits, accessibility and cost structure of unit trusts. The main benefits of a unit trust investment relate to its simplicity, ease of understanding, low risk as well as transparency, which makes it a good investment vehicle as it offers investors variety and freedom of choice (PSG Online, 2014c). Investors can choose from a variety of different types of securities and types of funds to invest in. Unit trusts provide investors an easy way to invest money (PSG Online, 2014a). Unit trusts are also designed to enable investors who want to enter the financial markets but do not have the time and expertise to invest directly, to do so (PSG Online, 2014b). Duncan (2013) and Lusardi et al. (2010:358) concur by stating that unit trusts provide a simple and effective way of saving money.

Investors can make use of different types of financial service providers to invest in unit trusts through them (PSG Online, 2014c). Unit trusts are managed for investors by professional fund managers (Oldert, 2014:55). Unit trusts are also well regulated as management companies, and other financial service providers trading in unit trusts, are required to operate these investments under mandates stipulated by the ASISA and the FSB (0ldert, 2014:50,54). However, potential investors should be wary of fund managers who overstate the performance outlook of unit trusts (Merkel, 2016).

In addition to being well regulated and managed, Duncan (2013) indicates that unit trusts are stable investment vehicles during all economic periods. The reason for this is that unit trusts cater for varying economic scenarios and risk tolerance levels across global asset classes. Unit trusts also allow investors long-term savings investment income, liquid investments and access to a wide variety of national and international investment vehicles (Mibiola, 2013:12; PSG Online, 2014a; PSG Online, 2014b). It is however important to note that the costs and returns of a unit trust are dependent on the composition of such a unit trust. Therefore, there exists a possibility that returns may fluctuate (Disadvantages of mutual funds, 2016).

Another benefit of unit trusts is that the value of an investor's unit can easily be determined (Oldert, 2014:50). Since the value of a unit trust is based on its net asset value (NAV) investors do not have the opportunity to compare unit trusts by using ratios such as the price-earnings ratio and earning per share ratio (Disadvantages of mutual funds, 2016). Linking to its value, unit trusts have convenient payment options as investors can arrange monthly debit orders (Oldert, 2014:42). Furthermore, investors can easily organise for the reinvestment of income from an unit trust investment (Oldert, 2014:42, 43). 
In addition to easy entry to financial markets for all types of investors through unit trusts, as mentioned before, the simplicity of purchasing and selling unit trusts adds to this investment vehicle's accessibility to the average investor (Oldert, 2014:42). Investors can trade in unit trusts via a financial service provider (such as a bank or independent financial advisor/planner), Management Company or the Internet (Oldert, 2014:42). According to Merkel (2016), due to investment execution strategies unit trusts may not be suitable for investors with short-term investment horizons.

Unit trusts' cost structure also makes this investment vehicle attractive to consumers. Unit trust investors' costs or fees include initial, ongoing, administrative, service, performance and taxation fees (PSG Online, 2014c). Management companies offering unit trust investments are required by legislation to disclose detailed information regarding the company's unit trust cost structure, which is monitored by the Collective Investment Schemes Act of 2002 (PSG Online, 2014b). However, the companies' individual unit trust fee structures charged to investors are not regulated (PSG Online, 2014b). Investors should be aware of the total expense ratio, advertising fees and sales charges linked to the investment, as the fees charged will reduce the unit trust's overall return (Merkel, 2016). Despite this, unit trusts are popular in South Africa due to the investment vehicle's cost transparency and the ease of determining its value (Oldert, 2014:42). As the minimum debit order amount can be as low as R100, unit trusts are regarded as affordable to the average investor (Oldert, 2014:33, 50).

\section{RESEARCH HYPOTHESES}

Based on the literature review, FIGURE 1 presents this study's hypothesised relationships between variables.

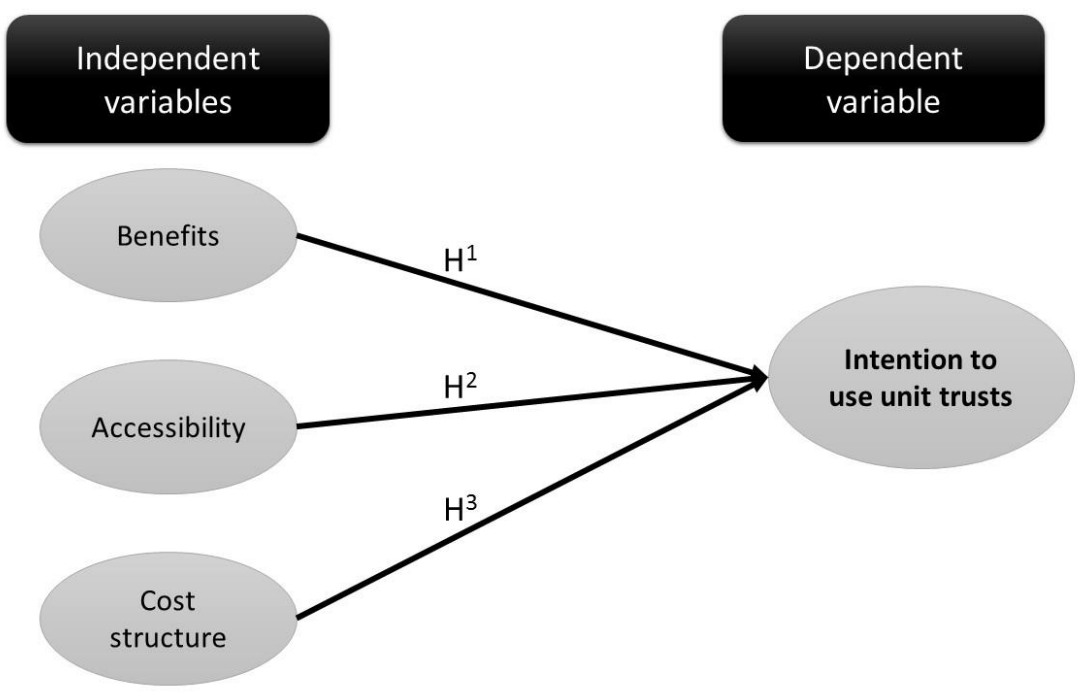

FIGURE 1: Hypothesised model of selected variables influencing the intention to use unit trusts

Source: Researchers' construct. 
The three hypotheses presented in FIGURE I were constructed to establish whether relationships exist between the three predetermined independent variables (Benefits, Accessibility, and Cost structure) and the dependent variable (Intention to use unit trusts).

$\mathrm{H}^{1}$ : The benefits of unit trusts increases consumers' intention to use unit trusts

$\mathrm{H}^{2}$ : The accessibility of unit trusts increases consumers' intention to use unit trusts

$H^{3}$ : The cost structure of unit trusts increases consumers' intention to use unit trusts

\section{RESEARCH METHODOLOGY}

\subsection{Data collection}

The primary objective of the study is to investigate consumers' perceptions of unit trusts by identifying the factors which influence consumers' intention to use unit trusts as an investment vehicle. In order to develop the hypothetical model to be tested in the empirical investigation, a literature review was conducted to gather relevant secondary data relating to unit trust investments. A quantitative approach was followed in this study as a hypothetical model was to be tested, and a large representative sample of the population was to be used for the primary data collection (Struwig \& Stead, 2013:3-4). The quantitative approach was appropriate as the researchers' aim was to determine whether relationships exist between the independent variables (Benefits, Accessibility and Cost structure) and the dependent variable (Intention to use unit trusts).

For the empirical investigation, the target population was all South Africans over the age of 18. However, due to geographic location, consumers over the age of 18 within the Nelson Mandela Metropolitan Area were identified as the group from which a sample was selected. As no sampling frame was available, the primary data was collected by means of non-probability convenience and snowball sampling which is recommended due to the accessibility and availability of the respondents (Bryman, Bell, Hirschsohn, Dos Santos, Du Toit, Masenge, Van Aardt \& Wagner, 2014:171, 178, 179). Fieldworkers gathered the responses of consumers within the metropolitan area and asked wiling respondents to suggest other potential respondents, i.e. their family and friends. Based on the number of variables and questionnaire items, a minimum sample size of 160 was deemed appropriate for this study. According to Bartlett, Kotrlik and Higgins (2001:48), to conduct a multiple regression analysis in a study, the ratio of observations to independent variables should not fall below five. In addition, the authors state that a more conservative ratio relates to 10 observations per independent variable. This study followed these guidelines: the study has three independent variables and will follow the guideline of ten observations per independent variable. In addition, the measuring instrument included a minimum of five items to measure each variable. This translates to a multiplication of three variables, with five items per variable and 10 respondents per variable, which indicates an acceptable minimum sample size of 150 .

A self-administered, structured questionnaire was used to collect data from the sample. This measuring instrument was adopted from a previous study which gathered the perceptions of young adults (aged 18 - 24 years) on unit trusts (Krüger \& Rootman, 2015). The measuring instrument was previously confirmed as valid and reliable, and therefore possible to use in future related studies. Section A comprised of 40 items pertaining to the three independent variables (Benefits, Accessibility and Cost structure) and the dependent variable (Intention to use unit 
trusts). This section used a nominal scale in the form of a five-point Likert-scale with the continuum of the ranging from 'strongly disagree' (1) to 'strongly agree' (5). Section B, using a ordinal scale, focused on gathering the biographic and demographic data of the respondents relating to their gender, population group, age, education level and data on the current investment vehicles they use. In addition, the respondents were also asked whether they have heard of unit trusts previously and if so, by means of an open question, how they would define unit trusts.

\subsection{Data analysis}

The computer programmes Microsoft Excel and Statistica Version 12 were used to capture and analyse the data. Descriptive statistics were used to summarise and describe the sample's biographic and demographic data (Struwig \& Stead, 2013:159). In addition, it was important to ensure that the measuring instrument was valid and reliable for the purposes of this study. Measures of validity are concerned with the integrity of the conclusions generated from a research study (Bryman \& Bell, 2011:42). As mentioned, the measuring instrument was adopted from a previous study, and therefore the content validity (Struwig \& Stead, 2014:146) was not again tested by means of a pilot study. However, to ensure construct validity (Bryman \& Bell, 2011:160), an exploratory factor analysis ( $(F A)$ was conducted. Factors with more than three items and factor loadings of at least 0.4 were considered as valid (Hair, Black, Babin \& Anderson, 2014:115). Measures of reliability consider whether the results of a study are repeatable (Bryman \& Bell, 2011:41). The Cronbach's Alpha correlation coefficient was calculated in order to assess the internal reliability of the measuring instrument. A Cronbach's Alpha coefficient limit of 0.60 was used, with items of a Cronbach's Alpha coefficient less than 0.60 being excluded from further analysis (Zikmund, Babin, Carr \& Griffin, 2010:302).

Following the validity and reliability analyses descriptive statistics such as means, standard deviations and frequencies (Davis, Pecar \& Santana, 2014:69, 102), concerning the resultant variables were calculated. The correlations or linear associations between the independent variables (Benefits, Accessibility and Cost structure) and dependent variable (Intention to use unit trusts) were determined by calculating the Pearson Product-Moment correlation coefficients (Davis et al., 2014:401). Lastly, a multiple regression analysis was performed to determine whether relationships exist between the independent variables and the dependent variable (Lind, Marchal \& Wathen, 2012:463). A T-test was performed between the categorical variable Gender and the independent and dependent variables Benefits, Accessibility and Intention to use unit trusts (Struwig \& Stead 2013:170). In addition, Analysis of Variance (ANOVA) tests were performed to determine whether the respondents from the various population groups, age groups, employment statuses and educational levels perceive Benefits, Accessibility and Intention to use unit trusts differently (Struwig \& Stead 2013:170-171). Bonferroni post-hoc tests were also performed to determine where the differences in perceptions occurred (Davis et al., 2014:605).

\section{EMPIRICAL RESULTS}

\subsection{Sample description}

The sample size was 509 respondents of which the majority was males (51\%) and $49 \%$ was females. The majority of the respondents were from the White population group ( $46 \%$ ) followed by the Black $(35 \%)$, Coloured (14\%) and Asian (2\%) population groups. The majority of the respondents were 
between the ages 18 and $24(39 \%)$, followed by the age groups 25 to $29(17 \%)$ and 30 to $34(10 \%)$. The age groups 35 to $39(7 \%), 40$ to $44(8 \%), 45$ to $49(6 \%), 50$ to 54 (7\%) and 55 to 59 (6\%) were also represented. A great percentage of the respondents were full time employed individuals $(44 \%)$, while $28 \%$ of the respondents were students at a tertiary institution with no employment. Approximately $10 \%$ of the respondents were self-employed, $9 \%$ were employed on a part-time basis and $5 \%$ were unemployed. Most of the respondents indicated that their highest qualification is Grade $12 /$ Matric (36\%), followed by respondents who obtained an undergraduate degree (21\%), post-graduate degree (17\%) and undergraduate diploma (11\%). A few respondents obtained a certificate $(7 \%)$ or a post-graduate diploma (5\%). The majority of respondents $(66 \%)$ had heard of unit trusts before. However, approximately $45 \%$ of respondents had not invested in any type of investment vehicle. Of those respondents with investments, most investments were in the form of shares $(n=142)$, cash $(n=135)$ and property $(n=124)$.

\subsection{Validity and reliability analyses}

The results of the eigenvalues showed that 11 factors should be extracted from an EFA. Of the 11 factors, four were removed from any further analysis due to cross-loadings and/or the loading of less than three items onto a factor. With factor loadings above 0.4 , the remaining seven factors were regarded as valid. However, after an initial measure of reliability, another four factors were removed from any further analysis as these factors had Cronbach Alpha correlation coefficients ranging between 0.494 and 0.576 . Cost structure was one of these four factors which were removed, due to a Cronbach Alpha correlation coefficient of 0.510 . Therefore, the remaining three factors where used for further data analyses.

The factor loadings from the EFA and the Cronbach Alpha correlation coefficient, together with the items which loaded onto the first factor, are provided in TABLE 1 .

\section{TABLE 1: Factor 1 - Benefits}

\begin{tabular}{|c|c|}
\hline \multicolumn{2}{|l|}{$B E N E F / T S$} \\
\hline Cronbach Alpha & 0.728 \\
\hline Item & Factor loadings \\
\hline (1) I will invest in unit trusts because they can be used for personal savings. & 0.708 \\
\hline $\begin{array}{l}\text { (2) I will invest in unit trusts because they can be used to save for } \\
\text { retirement. }\end{array}$ & 0.627 \\
\hline $\begin{array}{l}\text { (3) Investors' unit trusts are managed by skilled and knowledgeable } \\
\text { portfolio managers. }\end{array}$ & 0.589 \\
\hline (4) Unit trusts can be bought through financial advisors. & 0.512 \\
\hline (5) Unit trusts can be purchased by making regular monthly payments. & 0.484 \\
\hline
\end{tabular}

Source: Calculated from survey validity and reliability results

Considering the five items which loaded onto this factor, the factor was named Benefits, as all the items related to benefits resulting from a unit trust investment. For example, loaded items refer to unit trusts' savings benefits, beneficial payment options as well as the benefit that this investment vehicle can be purchased from and are managed by experienced financial service 
providers. Validity was evident as factor loadings for Benefits ranged between 0.409 and 0.708 . Sufficient evidence of reliability was also found as the Cronbach alpha for this factor was 0.728 .

Items which loaded onto the second factor, together with its EFA results and Cronbach Alpha correlation coefficient are shown in TABLE 2.

\section{TABLE 2: Factor 2 - Accessibility}

\begin{tabular}{lc}
\hline \multicolumn{2}{c}{ ACCESSIBILITY } \\
\hline \multicolumn{1}{c}{ Cronbach Alpha } & 0.721 \\
(1) Unit trusts are easily accessible. & 0.696 \\
(2) It is easy to find information about unit trusts in South Africa. & 0.688 \\
(3) Unit trusts can be bought online using the Internet. & 0.571 \\
(4) Unit trust can be bought from a unit trust management company. & 0.440 \\
(5) A specific unit trust can consist of shares from different sectors & 0.404 \\
(industries) on the JSE. & \\
\hline
\end{tabular}

Source: Calculated from survey validity and reliability results

As all five items which loaded on the second factor related to the accessibility of unit trusts, this factor was named Accessibility. Items related to unit trusts' accessibility in terms of the available information relevant to unit trusts, investors' accessibility to investments in different sectors as well as through unit trusts' purchasing options via the Internet and management companies. The factor loadings for Accessibilityranged from 0.404 to 0.696, which suggests validity. The Cronbach alpha was 0.721 and therefore sufficient evidence of reliability was found.

Lastly, TABLE 3 shows the items which loaded onto the third factor as well as its $\varepsilon F A$ results and Cronbach Alpha correlation coefficient.

TABLE 3: Factor 3 - Intention to use unit trusts

\begin{tabular}{lc}
\hline \multicolumn{2}{c}{ INTENTION TO USE UNIT TRUSTS } \\
\hline Cronbach Alpha & 0.658 \\
\hline Item & Factor loadings \\
(1) The net asset value (NAV) of the fund is the price of the unit trust. & 0.706 \\
(2) Unit trusts are a highly liquid investment. & 0.594 \\
(3) I will invest in unit trusts because I will have shares on the JSE. & 0.562 \\
(4) I will invest in unit trusts because they are easy to sell. & 0.486 \\
(5) I will invest in unit trusts because I will have access to international & 0.432 \\
\hline
\end{tabular}

Source: Calculated from survey validity and reliability results 
The third factor was named Intention to use unit trusts, as the five loaded items all considered whether consumers will invest in unit trusts in the future. Items linked to the facts that unit trusts are liquid, could ensure investments in shares and international funds, are easy to sell and unit trust prices are easy to find. The factor loadings ranged between 0.432 and 0.706 , and these loadings indicate the study's dependent variable is valid. Sufficient evidence of reliability was found as the Cronbach alpha for Intention to use unit trusts was 0.658 .

Based on the EFA results, the research hypotheses were reduced to the following:

$\mathrm{H}^{1}$ : The benefits of unit trusts increases consumers' intention to use unit trusts

$\mathrm{H}^{2}$ : The accessibility of unit trusts increases consumers' intention to use unit trusts

\subsection{Descriptive statistics of the variables}

The descriptive statistics of the variables are summarised in TABLE 4.

\section{TABLE 4: Descriptive statistics of variables}

\begin{tabular}{lccccc}
\hline \multicolumn{1}{r}{ INDEPENDENT VARIABLES } & Mean & Std. dev. & Disagree & Neutral & Agree \\
\hline Benefits & 3.951 & 0.610 & $0.982 \%$ & $22.004 \%$ & $77.014 \%$ \\
Accessibility & 3.659 & 0.640 & $3.340 \%$ & $34.971 \%$ & $61.690 \%$ \\
\multicolumn{1}{c}{ DEPENDENT VARIABLE } & Mean & Std. dev. & Disagree & Neutral & Agree \\
Intention to use unit trusts & 3.283 & 0.617 & $7.269 \%$ & $59.921 \%$ & $32.809 \%$ \\
\hline
\end{tabular}

Source: Calculated from survey descriptive statistics results

The independent variable Benefits obtained the highest mean of 3.951. This mean score indicates that respondents agree that they know about the Benefits unit trusts offer. The independent variable Accessibility obtained a mean of 3.659 . The mean score of this variable shows that respondents are neutral with a tendency towards agreeing that they know how to access unit trusts and information about unit trusts. The dependent variable Intention to use unit trusts, obtained a mean score of 3.283 . This mean score indicates that respondents are neutral with a slight tendency towards agreeing that they will invest in unit trusts in the future. When considering the standard deviations it is evident that the responses are closely distributed. The small standard deviations range from 0.610 for Benefits to 0.640 for Accessibility. Therefore, respondents mostly differed in their viewpoints on Accessibility, in other words, not all respondents had a similar view that unit trusts are easily accessible. More than $77 \%$ of the respondents agree that they are familiar with the Benefits offered by unit trusts. However, approximately only $33 \%$ of the respondents indicated that they intent to invest in unit trusts in the future.

\subsection{Analysis of relationships between the variables}

In terms of the Pearson correlation coefficient results, positive correlations exist between both the independent (Benefits and Accessibility) and the dependent (Intention to use unit trusts) variables. The strongest positive correlation exist between Benefits and Accessibility $(r=0.564)$. This shows that unit trusts' accessibility and benefits are strongly linked, therefore it is important 
that consumers are better informed or have access to information regarding the benefits of unit trusts. The links between the variables, evident from the Pearson correlation results, motivated that a multiple regression analysis be conducted to identify significant relationships between the variables.

The multiple regression analysis assessed whether any of the independent variables has a significant influence on the dependent variable Intention to use unit trusts. TABLE 5 summarises the multiple regression results.

\section{TABLE 5: The influence of Benefits and Accessibility on the Intention to use unit trusts}

\begin{tabular}{|c|c|c|c|c|c|c|}
\hline \multirow[b]{2}{*}{$N=509$} & \multicolumn{6}{|c|}{$\begin{array}{l}\text { Regression Summary for Intention to use unit trusts } \\
\mathrm{R}=0.522 ; \mathrm{R}^{2}=0.272 \\
\mathrm{~F}(2,506)=94.621 ; p<.000\end{array}$} \\
\hline & $b^{*}$ & $\begin{array}{c}\text { Std. Err. } \\
\text { of } b^{*}\end{array}$ & $b$ & $\begin{array}{c}\text { Std. Err. } \\
\text { of b }\end{array}$ & $t(506)$ & $p$-value \\
\hline Intercept & & & 1.091 & 0.164 & 6.648 & 0.000 \\
\hline Mean Benefits & 0.251 & 0.046 & 0.254 & 0.046 & 5.464 & 0.000 \\
\hline Mean Accessibility & 0.337 & 0.046 & 0.325 & 0.044 & 7.342 & 0.000 \\
\hline
\end{tabular}

Source: Calculated from survey multiple regression results

Approximately $27.22 \%$ of the variability in Intention to use unit trusts is explained by the independent variables Benefits and Accessibility. It is evident that both Accessibility $(b=0.325$, $p<.05)$ and Benefits $(b=0.254, p<.05)$ have significant positive relationships with Intention to use unit trusts. In other words, if the knowledge on the benefits of unit trusts increases, consumers might be encouraged to increase their use of unit trusts as an investment vehicle. In the same way, if the availability of unit trusts and the available information about unit trusts to consumers improve, these investors' might also be encouraged to increase their use of unit trusts. Based on the multiple regression results both hypotheses $\left(\mathrm{H}^{1}\right.$ and $\left.\mathrm{H}^{2}\right)$ are accepted $(p<.05)$, as significant positive relationships were found between each of the independent variables (Benefits and Accessibility) and the dependent variable (Intention to use unit trusts).

\subsection{T-test and ANOVA results}

The following research hypotheses were formulated for the t-test and ANOVA tests:

$H^{0, A}$ : There is no difference between the mean scores of Gender and Benefits

$H^{0, B}$ : There is no difference between the mean scores of Gender and Accessibility

$H^{0, c}$ : There is no difference between the mean scores of Gender and Intention to use unit trusts

$\mathrm{H}^{0, \mathrm{D}}$ : There is no difference between the mean scores of Population group and Benefits

$\mathrm{H}^{0, \varepsilon}$ : There is no difference between the mean scores of Population group and Accessibility

$\mathrm{H}^{0, \mathrm{~F}}$ : There is no difference between the mean scores of Population group and Intention to use unit trusts 
$\mathrm{H}^{0, G}$ : There is no difference between the mean scores of Age and Benefits

$\mathrm{H}^{0, \mathrm{H}}$ : There is no difference between the mean scores of Age and Accessibility

$\mathrm{H}^{0, \mathrm{I}}$ : There is no difference between the mean scores of Age and Intention to use unit trusts

$\mathrm{H}^{0, \mathrm{~J}}$ : There is no difference between the mean scores of Employment status and Benefits

$\mathrm{H}^{0, \mathrm{~K}}$ : There is no difference between the mean scores of Employment status and Accessibility

$\mathrm{H}^{0, \mathrm{~L}}$ : There is no difference between the mean scores of Employment status and Intention to use unit trusts

$\mathrm{H}^{0, \mathrm{M}}:$ There is no difference between the mean scores of Education leve/and Benefits

$\mathrm{H}^{0, \mathrm{~N}}$ : There is no difference between the mean scores of Education leve/and Accessibility

$\mathrm{H}^{0,0}$ : There is no difference between the mean scores of Education leve/ and Intention to use unit trusts

The results of the $t$-test are presented in TABLE 6 .

TABLE 6: $T$-test summary of Gender on the independent and dependent variables

\begin{tabular}{lcc}
\hline \multicolumn{1}{c}{ VARIABLES } & t-value & $p$-value \\
\hline Benefits & -0.530602 & 0.595928 \\
Accessibility & 0.510877 & 0.609660 \\
Intention to use unit trusts & 0.030983 & 0.975295 \\
\hline
\end{tabular}

Source: Obtained from survey $t$-test results

Based on TABLE 6, male and female respondents did not differ $(p>.05)$ in terms of their perceptions regarding the benefits of unit trusts, accessibility of unit trusts and their intention to use unit trusts as an investment vehicle. Therefore hypotheses $\mathrm{H}^{0, \mathrm{~A}}, \mathrm{H}^{0, \mathrm{~B}}$ and $\mathrm{H}^{0, \mathrm{C}}$ are accepted as no differences exist.

TABLE 7 summarises the ANOVA results.

From TABLE 7 it is evident that the respondents from the various population groups do not differ in terms of their perceptions regarding the benefits of unit trusts, the accessibility of unit trusts and their intention to use unit trusts as an investment vehicle. Therefore hypotheses $\mathrm{H}^{0, \mathrm{D}}, \mathrm{H}^{0, \varepsilon}$ and $\mathrm{H}^{0, \mathrm{~F}}$ are accepted as no differences exist.

However, respondents of various age groups and with different employment statuses have different perceptions regarding the benefits of unit trusts, the accessibility of unit trusts and their intention to use unit trusts as an investment vehicle. Therefore hypotheses $\mathrm{H}^{0, \mathrm{G}}, \mathrm{H}^{0, \mathrm{H}}, \mathrm{H}^{0, \mathrm{O}}, \mathrm{H}^{0, \mathrm{~J}}, \mathrm{H}^{0, \mathrm{~K}}$ and $\mathrm{H}^{0, \mathrm{~L}}$ are rejected as differences do exist.

In addition, the education levels of the respondents also influence their perceptions regarding the benefits and accessibility of unit trusts, but not with regard to their intention to use unit trusts as an investment vehicle. Therefore hypotheses $\mathrm{H}^{0, \mathrm{M}}$ and $\mathrm{H}^{0, \mathrm{~N}}$ are rejected as differences do exist while hypothesis $H^{0,0}$ is accepted as no difference exists. 
TABLE 7: Summary of ANOVA results of various categorical data on the independent and dependent variables

\begin{tabular}{lcc}
\hline \multicolumn{1}{c}{ VARIABLES } & F-value & p-value \\
\hline Benefits & Population group & \\
Accessibility & 0.300 & 0.937 \\
Intention to use unit trusts & 0.509 & 0.802 \\
& 1.656 & 0.130 \\
\hline Benefits & Age & \\
Accessibility & 3.861 & 0.000 \\
Intention to use unit trusts & 3.133 & 0.003 \\
& 2.627 & 0.011 \\
\hline Benefits & Employment status & \\
Accessibility & 5.132 & 0.000 \\
\hline Intention to use unit trusts & 2.856 & 0.004 \\
\hline Bccessibility & 3.379 & 0.001 \\
\hline Intention to use unit trusts & 3.667 & 0.001 \\
\hline Education level & 0.481 & 0.848 \\
\hline
\end{tabular}

Source: Obtained from survey ANOVA results

$\star p<.05$

In order to determine where the differences in perceptions lie, Bonferroni tests were performed. This differences are translated by the mean scores, and the results show that respondents in both the age groups 50 to $54(M=4.142)$ and 55 to $59(M=4.186)$ perceive the benefits of unit trusts to be more than the respondents in the age group 18 to $24(M=3.793)$. With regards to accessibility, the respondents in the age group 18 to $24(M=3.533)$ regard units trust to be less accessible than respondents in the age group 50 to $54(M=3.926)$. Although the ANOVA test revealed the existence of differences, the post-hoc Bonferroni test did not reveal any significant differences in the perceptions of the various age groups in terms of their intention to use unit trusts.

The results show that both part time employed respondents $(M=4.047)$ and self-employed respondents $(M=4.188)$ regard unit trusts as providing more benefits than respondents that are students with no employment $(M=3.731)$. Furthermore, self-employed respondents $(M=3.953)$ view unit trusts to be more accessible than respondents that are students with no employment ( $M$ $=3.510)$. As with benefits, in terms of intention to use unit trusts, both part time employed respondents $(M=3.287)$ and self-employed respondents $(M=3.616)$ have an higher intention to use unit trusts than the respondents that are students with no employment $(M=3.150)$. 
With regard to the education level, the respondents with a Grade $12 /$ Matric $(M=3.848 ; M=3.547)$ and the respondents with a post-graduate degree $(M=4.1465 ; M=3.933)$ hold different perceptions regarding the benefits of unit trusts as well as the accessibility of unit trusts respectively. Respondents with post-graduate degrees consider unit trusts to have more benefits and to be more accessible that what the Grade 12/Matric qualified respondents perceive.

\section{PRACTICAL RECOMMENDATIONS}

The primary objective of the study was to investigate consumers' perceptions of unit trusts by identifying the factors which influence consumers' intention to use unit trusts as an investment vehicle. The study's objective was attained as the main empirical results showed that based on consumers' perceptions, the factors benefits and accessibility significantly influence consumers' intention to use unit trusts. Therefore, a number of strategies are hereby given to financial service providers in order to increase consumers' intention to use, and therefore possibly their actual use, of unit trusts as investment vehicles.

Based on the study's results, TABLE 8 presents the strategies recommended to ensure that consumers are aware of the benefits of unit trust investments.

\section{TABLE 8: Strategies to ensure consumers' awareness of unit trust benefits}

Ensure that the benefits of unit trust investments are clearly communicated to, and understood, by the general public, in particular potential investors.

When marketing unit trusts as investment vehicles, stress the opportunity of saving which unit trusts provide to investors. Consumers should realise the immediate monetary as well as long-term saving benefits, for example at the time of retirement, resulting from unit trust investments. The current low household savings rate proves that consumers are struggling to save. Use the fact that unit trusts are savings mechanisms to encourage unit trust investments.

Emphasise that unit trusts are managed for investors by skilled, trained and knowledgeable financial service providers and unit trust management companies. Individual investors do not require financial and investment knowledge relating to unit trusts. Financial and investment advice are available from financial service providers.

Inform consumers about the affordable and convenient payment options when purchasing unit trusts, for example monthly instalments.

Source: Researchers' construct

TABLE 9 describes the strategies useful to ensure that consumers view unit trusts investments, and information about unit trusts, as accessible, as well as are able to access or invest in unit trusts easily.

In addition to these recommendations presented in TABLES 6 and 7, which focuses on the benefits and accessibility of unit trusts, it should be noted that consumers intent to invest in unit trusts then they know that unit trusts are liquid, could ensure investments in shares and international funds, are easy to sell and unit trust prices are easy to find. Therefore, these aspects should also be clearly communicated to, and understood by, the general public, in particular potential investors, as their intention to invest in unit trust will then increase. 
TABLE 9: Strategies to ensure consumers' accessibility to unit trusts and related information

Ensure that unit trust investment information is as available to consumers as banking information, which is consistently communicated or marketed by South African banks.

Inform consumers that unit trust investments can be made via the Internet and by directly consulting financial service providers and unit trust management companies.

Explain that the composition of a unit trust investment allows for diversification as investments can be made in a variety of financial securities (e.g. share investments in companies listed in different JSE categories).

Source: Researchers' construct

With regard to the t-test, ANOVA tests and Bonferroni tests results, it is recommended that financial service provides spend more time on informing younger, lower educated communities and students without employment about the benefits and accessibility of unit trusts. It was evident that younger respondents and respondents with lower educational levels are not currently aware and knowledgeable about unit trusts as investment vehicles. Due to unit trusts being more affordable to low-income earners or the average investor than other investment vehicles, these results reveal an opportunity in the market for financial service providers.

\section{FUTURE RESEARCH AND FINAL CONCLUSION}

It should be noted that the sample of the study was selected through convenience sampling and was limited to one geographical area in South Africa. This hinders the generalisability of the results to the population of the study. As the perceptions on investment vehicles might differ due to consumers in different geographical areas having varied levels of income and debt, future research on consumers' perceptions of unit trusts should be extended to include more geographical areas.

Despite these limitations it is evident that the practical recommendations suggested in this study should enable financial service providers to encourage and therefore increase consumers' investments in unit trusts. Specifically, the contribution of this study could positively influence South Africa's savings rate and improve citizens' financial wellbeing. One of the study's main contributions stems from the fact that it filled a research gap in terms of investigating consumers' perceptions of unit trusts in South Africa. The study thus paves the way for future research relating to unit trust investments as well as research on other investment vehicles.

\section{LIST OF REFERENCES}

Aron, J. \& Muellbauer, J. (2011). Wealth, credit conditions and consumption: Evidence from South Africa, Department of Economics, University of Oxford. (Discussion paper series no. 580).

Bartlett, J.E., Kotrlik, J.W. \& Higgins, C.C. (2001). Organizational research: Determining appropriate sample size in survey research. Information Technology, Learning, and Performance Journal, 19(1), pp. 43-50. 


\section{Rootman \& Krüger}

Braunstein, S. \& Welch, C. (2002). Financial literacy: An overview of practice, research and policy. Available:

http://heinonline.org/HOL/LandingPage?handle=hein.journals/fedred88\&div=158\&id=\&page

(Accessed 27 October 2014).

Bryman, A. \& Bell, દ. (2011). Business research methods. $3^{\text {td }}$ edition. New York: Oxford.

Bryman, A., Bell, E., Hirschsohn, P., Dos Santos, A., Du Toit, J., Masenge, A., Van Aardt \& Wagner, C. (2014). Research methodology: Business and management contexts. Cape Town: Oxford.

Collins, D. \& Morduch, J. (2007). Banking low-income populations: Perspectives from South Africa. Proceedings of the Access, Assets and Poverty Conference, 11-12 0ctober, Washington, DC.

Davis, G., Pecar, B. \& Santana, L. (2014). Business statistics using Excel: A first course for South African students. Cape Town: 0xford.

Dempsey, P. (2011). Family debt crisis: 5 lessons from the Eurozone. Association for Savings and Investment South Africa (ASISA). Available:

http://itinews.co.za/print.aspx?type $=2$ \&itemid $=3270 E 0 F D-3 F A 8-45 A B-906 B-34 D 5 C C 155 B 2 C$

(Accessed l September 2014).

Disadvantages of mutual funds. (2016). Available:

http://www.nasdaq.com/investing/disadvantages-of-mutual-funds.stm (Accessed 5 February 2016).

Duncan, J. (2013). Unit trusts facilitating real term wealth creation. FA News, 25 June. Available: http://www.fanews.co.za/article/investments/8/unit-trusts/1008/ unit-trusts-facilitating-realterm-wealth-creation/13797 (Accessed on 19 March 2014).

Faurie, J. (2014). The true motive behind regulation: is the FSB working towards improvement? FA News, 9 April. Available: http://www.fanews.co.za/article/front-page-features/25/thestage/1145/the-true-motive-behind-regulation-is-the-fsb-working-towards-improvement/15800 (Accessed on 18 May 2014).

FinMark Trust. (2012). Survey highlights: Finscope scope South Africa. Available:

http://www.finmark.org.za/wpcontent/uploads/pubs/FinScope_SA_Booklet_2012.pdf (Accessed 31 July 2013).

FinMark Trust. (2014). FinScope South Africa 2014. Available: http://www.finmark.org.za/wpcontent/uploads/pubs/Broch_FS_SA_FNL.pdf (Accessed 20 August 2015).

FSB. (n.d.). Financial Services Board. Available:

https://www.fsb.co.za/feedback/Documents/Saving.pdf (Accessed 20 August 2014).

Hair, J.F., Black, W.C., Babin, J.B. \& Anderson, R.E. (2014). Multivariate data analysis. $7^{\text {th }}$ edition. Essex, England: Pearson.

Incentivising non-retirement savings. (2012). Technical discussion paper D for public comment. Pretoria: South African National Treasury.

Jonas, M.H. (2014). Launch of the 2014 Savings Month. 3 July. Sandton: Ministry of Finance, South Africa.

Karlan, D., Ratan, A.L. \& Zinman, J. (2014). Savings by and for the poor: A research review and agenda. The Review of Income and Wealth, 20(1), pp. 37-78. 
Krüger, J. \& Rootman, C. (2015). Unit trusts as an investment vehicle: Young adults' perceptions. Papaper presented at the $5^{\text {th }}$ International Conference on Financial Services, 29 September-1 October 2015, Port Elizabeth, South Africa.

Lewis, S. \& Messy, F. (2012). Financial education, savings and investments: An overview. OECD Publishing. (OECD Working Papers on Finance, Insurance and Private Pensions, no. 22).

Lind, D.A., Marchal, W.G. \& Wathen, S.A. (2012). Statistical Techniques in Business \& Economics. New York, NY: McGraw-Hill.

Lusardi, A., Mitchell, 0.S. \& Curto, V. (2010). Financial literacy among the young. The Journal of Consumer Affairs, 44(2), pp. 358-380.

Maisel, C. (n.d.). South Africa is a buy now, pay later society: How do we change this to save now and pay later culture. Available: http://www.soulcity.org.za/projects/soul-buddyz/soul-buddyz-series3/literature-review/financial-literacy-and-management (Accessed 3 June 2012).

Merkel, S. (2016). What are the advantages and disadvantages of mutual funds? Available: http://www.investopedia.com/ask/answers/10/mutual-funds-advantagesdisadvantages.asphttp://www.investopedia.com/ask/answers/10/mutual-funds-advantagesdisadvantages.asp (Accessed 5 February 2016).

Mibiola, 0.J. (2013). Performance evaluation of unit trusts in South Africa over the last two decades. Available: http://wiredspace.wits.ac.za/bitstream/handle/10539/129

59/performance $\% 20$ evaluation $\% 20$ of $\% 20$ unit $\% 20$ trusts $\% 20$ in $\% 20$ south $\% 20$ africa $\% 20$ over $\% 20$ the $\% 2$ 0last\%20two\%20decades.pdf? sequence=1 (Accessed 18 May 2014).

Mongale, I.P., Mukuddem-Petersen, J., Petersen, M.A. \& Meniago, C. (2013). Household savings in South Africa: An econometric analysis. Mediterranean Journal of Social Sciences, 4(13), pp. 519-530.

0ECD. (2011). Household savings. OECD Factbook 2011-2012: Economic, Environmental and Social Statistics. 0ECD Publishing.

Oldert, N. (ed.) (2014). Profile's unit trusts \& collective investments. March 2014. Johannesburg: Profile Media.

Precious, C. \& Asrat, T. (2014). Determinants of household saving in South Africa: An econometric approach (1990-2011). Mediterranean Journal of Social Sciences, 5(15), pp. 183-190.

PSG Online. (2014a). Shares are essential to your long-term investment strategy. Available: http://news.psgonline.co.za/2013/11/shares-are-essential-to-your-long-term-investmentstrategy/ (Accessed on 18 May 2014).

PSG Online. (2014b). Unit trusts. Available: http://www.psgonline.co.za/ invest/unittrusts.php\#whatarethebankingsdeatils? (Accessed on 31 March 2014).

PSG Online. (2014c). Introduction to collective investments. Available:

http://www.psgonline.co.za/resources/Introduction-to-Collective-investments.php (Accessed on 19 March 2014).

Roberts, B., Struwig, J. \& Gordon, S. (2014). Financial Literacy in South Africa: Results from the 2013 South African Social Attitudes Survey round. Prepared by the HSRC on behalf of the FSB. Pretoria: Financial Services Board.

SAICA. (2013). Fostering a strong savings culture in South Africa. 15 July. Available: https://www.saica.co.za/News/NewsArticlesandPressmediareleases/tabid/695/itemid/4160/langua ge/en-US/Default.aspx (Accessed 20 August 2015). 
Saini, Y., Bick, G. \& Abdulla, L. (2011). Consumer awareness and usage of Islamic banking products in South Africa. South African Journal of Economic and Management Sciences, 14(3), pp. 298-313.

Sithebe, A. (2014). South African household savings and the influence of financial liberalisation. Unpublished MBA dissertation. Pretoria: University of Pretoria.

Soman, D. \& Cheema, A. (2011). Earmarking and partitioning: Increasing saving by low-income households. Journal of Marketing Research, XLVIII (Special Issue), pp. S14-S22.

Stokes, G. (2008). A closer look at professionalism in the financial services industry. FA News. 22 February. Available: http://www.fanews.co.za/article/front-page-features/25/featuredstory/1147/a-closer-look-at-professionalism-in-the-financial-services-industry/3882 (Accessed on 19 May 2014).

Struwig, F.W. \& Stead, G.B. (2013). Research: Planning, designing and reporting. $2^{\text {nd }}$ edition. Cape Town, South Africa: Pearson.

Zikmund, W.G., Babin, B.J., Carr, J.C. \& Griffin, M. (2010). Business research methods. $8^{\text {th }}$ edition. Mason, OH: South-Western. 